\title{
The effects of food abundance and disturbance on foraging flock patterns of the wintering Hooded Crane (Grus monacha)
}

Ling Yang ${ }^{1,2,3}$, Lizhi Zhou ${ }^{1,2,3^{*}}$ and Yunwei Song ${ }^{4}$

\begin{abstract}
Background: Food abundance and availability affect flock patterns of foraging birds. Cost and risk tradeoffs are especially critical for flocks of wintering waterbirds foraging in lake wetlands. Waterbirds losing suitable habitats face insufficient food supplies and high levels of disturbance, affecting their foraging activities. Our objective was to study the effects of food abundance and disturbances on flock size and the structure of Hooded Crane flocks wintering at Shengjin Lake and, as well, to understand the response of wintering waterbirds to habitat degradation for future management decisions and protection of the population.

Methods: We investigated food abundance, disturbances and flock foraging activities of the wintering Hooded Crane in several foraging habitats of Shengjin Lake from November 2013 to April 2014. Flock size and structure were observed by scan sampling. Data on food abundance and disturbances were collected by sampling. Flock size and structure were compared among three wintering stages. The relationship between food resources, disturbances and flock size were illustrated using a generalized linear model.

Results: In the early and middle wintering periods, the Hooded Crane used paddy fields as its major foraging habitat, where the number of foraging birds and flocks were the highest. During the late period, the cranes took to meadows as their major foraging habitat. The variation among foraging flock was mainly embodied in the size of the flocks, while the age composition of these flocks did not change perceptibly. Family flocks were notably different from flock groups in size and age composition. The results of a generalized linear model showed that the food abundance had a marked effect on foraging flock size and age composition, while disturbances had a significant effect only on flock size. From our analysis, it appeared that the combined effect of the two variables was significant on the size of the foraging flock, but had less impact on age composition.
\end{abstract}

Conclusions: Food abundance and disturbances affected the flock size of the Hooded Crane. With abundant food and high disturbances, flock sizes increased owing to cooperation in foraging. To avoid competition and maximize foraging benefits, flock size reduces with an abundance of food but low disturbance. By trading off risks and costs, the cranes showed flexible flock distributions and a variety of foraging strategies to maximize benefits and to improve their fitness.

Keywords: Flock pattern, Food abundance, Disturbance, Hooded crane

\footnotetext{
* Correspondence: zhoulz@ahu.edu.cn

${ }^{1}$ School of Resources and Environmental Engineering, Anhui University, Hefei

230601, China

${ }^{2}$ Institute of Biodiversity and Wetland Ecology, Anhui University, Hefei

230601, China

Full list of author information is available at the end of the article
}

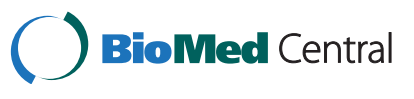

(c) 2015 Yang et al. This is an Open Access article distributed under the terms of the Creative Commons Attribution License (http://creativecommons.org/licenses/by/4.0), which permits unrestricted use, distribution, and reproduction in any medium, provided the original work is properly credited. The Creative Commons Public Domain Dedication waiver (http:// creativecommons.org/publicdomain/zero/1.0/) applies to the data made available in this article, unless otherwise stated. 


\section{Background}

Foraging in groups offers important benefits for individual birds as members of a group, such as increasing their likelihood of finding food or detecting and avoiding predators (Elgar 1989). Flocking is a common collective behavior of waterbirds, ensuring that the birds are able to spend a larger amount of time foraging rather than conducting anti-predator behavior (Yasué 2005; Beauchamp 2012). Flocking is important for saving foraging time and improving the efficiency of foraging (Beauchamp 2005; Michelena and Deneubourg 2011). Food abundance and risk of predation are key factors affecting bird groups into flocking in foraging habitats (Conradt 1998; Heithaus 2005; Luo et al. 2012; Beauchamp 2013). It is expected that habitats with a higher risk of predation will result in larger foraging flocks and that scarcity of resources will lead to smaller foraging flocks (Kotler et al. 1991; Abramsky et al. 1996; Beauchamp 2009). When food resources are scarce, strong foraging competition will lead to a shortage of foraging opportunities. Due to the scarcity of resources and competition pressure on flocks, the size and structure of the flocks will change. High predation risk has also an effect on flock patterns (Azevedo et al. 2010). In order to obtain enough food, birds stay alert for potential danger in their surroundings during foraging ( $\mathrm{Li}$ et al. 2012), causing a corresponding reduction in foraging time and opportunity; therefore, predation risk can be considered a foraging cost (Brown and Kotler 2004). Birds are usually apt to accept a less food supply in safer habitats (Lima and Dill 1990; Lima 1998). Some birds would rather forage in high-risk habitats with an abundant food supply (Heithaus and Dill 2002; Barta et al. 2004; Heithaus 2005).

According to the theory of optimal foraging, birds constantly keep adjusting their foraging strategy to adapt to changes in foraging habitats in order to maximize energy intake and minimize predation risk (Kuwae et al. 2010; Sirot et al. 2012). Adjustment of foraging flock patterns is an important embodiment of shifts in foraging strategy. If foragers gather in large groups in habitats with abundant food and high predation risk, they would take advantage of their flock effect to get enough food and reduce the risk of predation (Bekoff 1995; Bahr and Bekoff 1999; Li et al. 2011). By risk and cost tradeoffs of foraging activity, birds opt for suitable habitats and foraging flock patterns (Hansen et al. 2009; Kuwae et al. 2010).

The Hooded Crane is a large migratory East Asian wader, recognized as a vulnerable species in the IUCN Red List of Threatened Species (BirdLife International 2014) and as a grade I species in the China Key Protected Wild Animal List. Their global population consists of approximately 11600 individual cranes (Zhou et al. 2010). Each year, there are about 1000 individual cranes wintering in the wetlands of the middle and lower Yangtze River floodplain. Shengjin Lake is one of the most important wintering sites accommodating one third of all the Hooded Cranes in China (Zhou et al. 2009). The cranes forage in group, where the smallest unit is a family (Wang 1988; Ma et al. 2003; Masatomi 2004). More recently, the foraging habitats of wintering Hooded Cranes have been seriously degraded owing to human activities, especially by high density cage aquaculture and crab fishery, as well as by livestock and poultry raising. The amount of submerged plant material, such as Vallisneria natans and Potamogeton wrightii which are suitable winter food for Hooded Cranes, is declining (Liu et al. 2001; Xu et al. 2008; Fox et al. 2011).

Degradation of lake wetlands and seasonal hydrological fluctuations lead to changes in available food resources (Jing et al. 2007). Hooded Cranes forage in several habitats, such as paddy fields, meadows and mudflats (Zhao et al. 2013). Changes in foraging habitats bring new environmental pressures. It is therefore worthwhile to study whether the Hooded Crane would change its foraging flock pattern as a response to environment changes. Our study had two aims: a) to investigate the distribution of a foraging flock and its flock pattern of Hooded Cranes wintering at Shengjin Lake, and b) to study how food abundance and disturbance affect the size and structure of a wintering flock, in order to shed light on the response of Hooded Cranes to changes in food abundance and disturbance in degenerated foraging habitats.

\section{Methods}

\section{Study area}

Shengjin Lake $\left(30^{\circ} 16^{\prime}-30^{\circ} 25^{\prime} \mathrm{N}, 116^{\circ} 59^{\prime}-117^{\circ} 12^{\prime} \mathrm{E}\right)$ is located near Chizhou City, Anhui Province. It is a shallow lake connected to the Yangtze River, covering 33,300 ha. The lake is an important stopover and wintering ground for migratory waterbirds on the East Asian-Australian flyway (Barter et al. 2004; Zhou et al. 2010; Chen and Zhou 2011). The lake is in a subtropical humid monsoon climate zone, with clearly defined dry and wet seasons, an annual average temperature of $16.5-16.7^{\circ} \mathrm{C}$ and annual precipitation of $1291.33-1322.23 \mathrm{~mm}$. Affected by rainfall and a reversing river flow, the lake has clear seasonally hydrological fluctuations. Mudflats and meadows are widely exposed during the dry season from November to April with water levels dropping, forming suitable wintering sites for migratory waterbirds (Chen and Zhou 2011; Cong et al. 2011). The exposure of mudflats and meadows change with the water levels in the lakes during winter periods. The dominant hygrophilous plants are Carex tristachya, Potentilla supina, Polygonum hydropipe, Ranunculus polii and Phalaris arundinacea (Liu et al. 2001; Fox et al. 2011). Submerged plants include Potamogeton wrightii, Potamogeton crispus, Vallisneria natans and Ceratophyllum demersum (Wang 1988; Xu et al. 2008; 
Fox et al. 2011). A recent development is the deterioration and degeneration of lake habitats, as the result of a culture of overfishing. Some waterbirds were forced to turn to neighboring paddy fields to obtain their supplementary food supply (Czech and Parsons 2002; Wood et al. 2010).

The forage habitats of the wintering Hooded Crane are mainly located in the upper area of Shengjin Lake (Fig. 1). Tongxin, Bailian, Shegan and Yang'etou are the main foraging sites, with Dazhou, Xinjun and Chi'an as temporary foraging sites (Zhou et al. 2010; Zhao et al. 2013). In these areas, the cranes have no obvious predators, while the major predation risk comes from human disturbances (Zhou et al. 2010).

\section{Division of wintering periods and foraging flocks}

Given the prevailing climate features, hydrological fluctuation and wintering activity of the cranes (Wang et al. 2009; Zhou et al. 2009), we defined the period from early
November to late December as the early wintering stage; the period from early January to late February of the following year as the middle of the wintering period and the period from early March to the time when the cranes fly away as the late stage of the wintering period (Zhou et al. 2010). We identified individual cranes in a flock within a distance of $30 \mathrm{~m}$ (Wang et al. 2011; Xu et al. 2013). Furthermore, we distinguished family group cranes and flock group cranes according to the different composition of the flocks (Avilés 2003; Liu et al. 2008; Zhou et al. 2009). Family flocks consisted of no more than four individuals, i.e., two adult cranes with 0-2 juveniles. Flock group cranes consisted of more than one family occurring within $30 \mathrm{~m}$ of each other and included at least five cranes (Xu et al. 2013).

\section{Habitat survey}

We conducted field investigations from November 2013 to April 2014 and discovered the major foraging spots

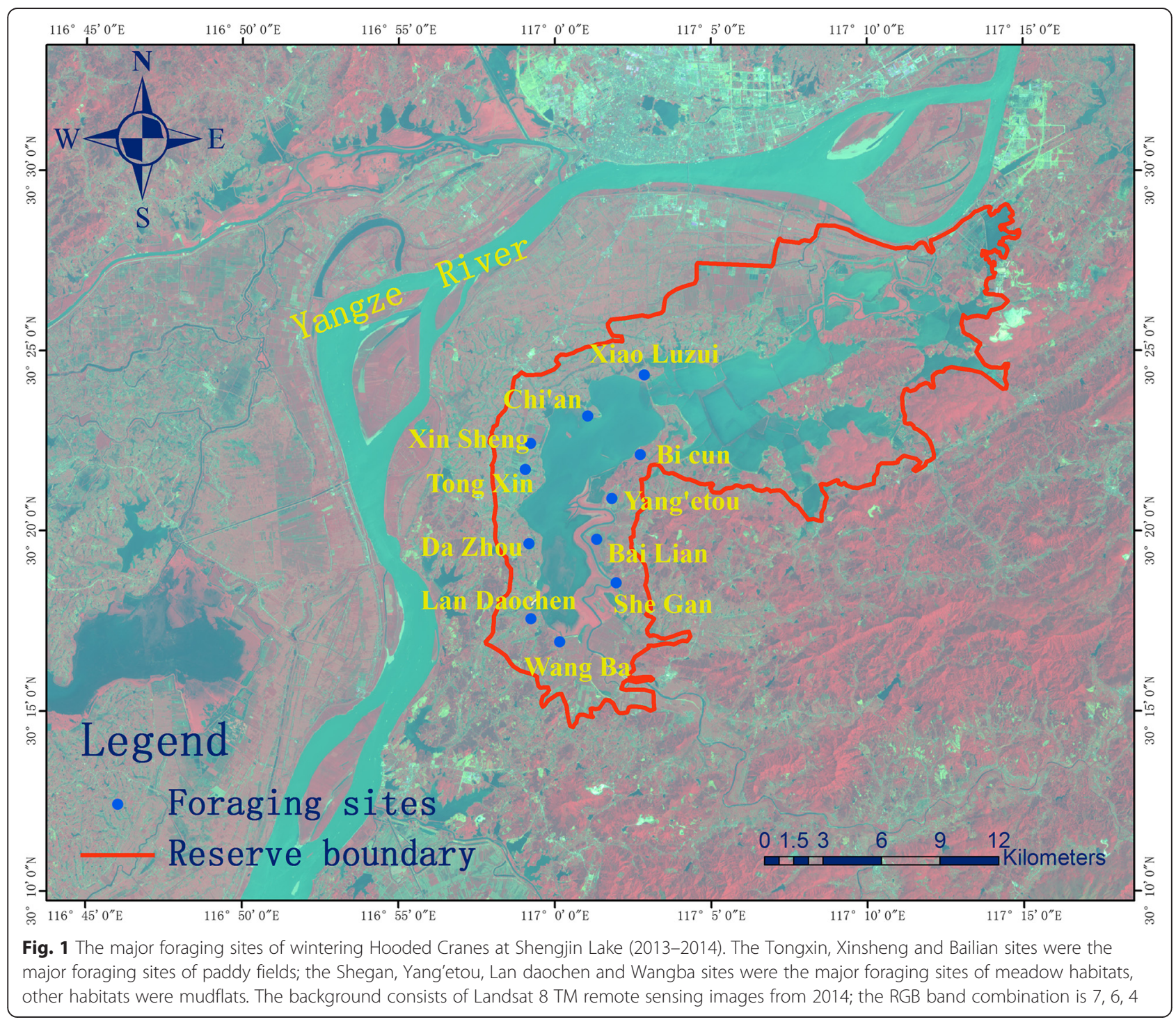


of the wintering Hooded Cranes. We used sampling methods to conduct investigations on habitat factors. Within a $100 \mathrm{~m}$ range of the foraging activities of cranes, we established $10 \mathrm{~m} \times 10 \mathrm{~m}$ quadrats, centered by GPS (eTrex30, Garmin, China) and at each of the four corners we set up $0.5 \mathrm{~m} \times 0.5 \mathrm{~m}$ sub-quadrats (Ma et al. 2003). We collected information on abundance of food resources and intensity of disturbances. During the three over-wintering periods, 258 quadrat samples were collected, of which 30, 25 and 30 in meadows, 32, 29 and 30 in paddy fields and 29, 23 and 30, in mudflats from the early, middle to late wintering stage, respectively.

We collected food from within $15 \mathrm{~cm}$ of the foraging subsurface, i.e., the approximate length of the bill of the Hooded Crane (Wang 1988). The roots of aquatic vegetation, the entrails of mollusks and rice grains were collected. After cleaning and sorting, we dried these food items at $65{ }^{\circ} \mathrm{C}$ in an oven (YHG-9050A; Derip, Suzhou, China) to a constant weight (g) to obtain their food abundance (biomass in $\mathrm{g} \cdot \mathrm{m}^{-2}$ ). According to the frequency and distance of disturbances observed during the survey, we divided the intensity of disturbances into three grades (Jiang et al. 2007). Finally, we defined the few passers-by, livestock and boats within a distance of 200-500 m to the crane flocks as a low degree of disturbance. Passers-by, vehicles and powerboats within a distance of 100 to $200 \mathrm{~m}$ were defined as a medium degree of disturbance and disturbances within a distance of $100 \mathrm{~m}$ were regarded as a high degree of disturbance.

\section{Flock survey}

We chose appropriate spots to observe the foraging activities of the cranes with the monocular telescope (SWAROVSKI 20-60*85) and the binoculars (BOSMA $8 * 42$ ). When flocks were stable and individual cranes became visible, we started to collect foraging flock data by instantaneous scan sampling at intervals of $5 \mathrm{~min}$ from 7:00 to 18:00 (Altmann 1974; Azevedo et al. 2010; Zhou et al. 2010).

We recorded the variables of flocks, such as the crane number, size, age composition and the type of foraging habitat. We used a direct-counting method to record the number of flocks, as well as the number of individual cranes in each flocks and distinguished the juveniles from adults by body size, head and neck color (Zhou et al. 2010). When the size of a flock changed or a flock of cranes flew away, we abandoned our observations and eliminated the collected data if the effective observation time was less than $30 \mathrm{~min}$. We postponed observation to avoid the effect of extreme weather when we met with strong winds, thick fog or heavy snow (Zhou et al. 2009; Xu et al. 2013). During the entire wintering period we investigated 276 flocks, of which 29, 20 and 63 were in meadows; 54, 45 and 11 in paddy fields and 22, 25 and 7, in mudflats during the early, middle and late wintering stages.

\section{Data analysis}

Combining the distribution of crane sites from GPS and the Minimum Convex Polygon Method, we obtained the distribution data of the foraging habitats (Terence et al. 2004) (Fig. 2). We studied the responses of foraging flock of cranes to the change of food abundance and disturbances by analyzing their foraging distribution at the three phases of the wintering period. We used the ratio of the relative number of individual cranes and flocks in a given habitat to the total number of individual cranes and flocks in all habitats to represent the foraging distribution of the cranes in that particular habitat (Zhao et al. 2013) and defined the ratio of the number of juveniles in a flock to the number of adults in the same flock as the age composition of the flock.

The data of food abundance, disturbances, flock size and age composition were tested for normality by using the one-sample Kolmogorov-Smirnov test. If the data followed a normal distribution we analyzed them in a one-way ANOVA or a $t$-test; if the data did not follow a normal distribution we used the non-parametric of KruskalWallis $\mathrm{H}$ tests and the Mann-Whitney $\mathrm{U}$ tests. In addition, the effect of food abundance and disturbances on the foraging flock was analyzed with a generalized linear model. All analyses were conducted with the SPSS 18.0 statistical package (SPSS, Chicago, IL, USA). A significance level of $0.05(p)$ was used for all statistical tests, with means stated as mean \pm SD.

\section{Results}

\section{Composition and distribution of foraging flocks}

In the early wintering period, individual cranes in the paddy fields accounted for $60.8 \%$ of the total number of cranes and their flocks for $51.43 \%$ of the total number of flocks; in the meadows these accounted for $28.8 \%$ and $27.62 \%$, in the mudflats for $10.4 \%$ and $20.95 \%$, respectively (Table 1 ). During the middle stage, the number of cranes in the paddy fields increased and accounted for $70.8 \%$ of the total number of cranes and $50 \%$ of the total number of flocks; in the meadows their numbers accounted for $15 \%$ and $22.22 \%$, in the mudflats for $14.2 \%$ and $27.8 \%$, respectively (Table 1 ). In the late period, the number of cranes in the meadows accounted for up to $85.1 \%$ of the total and for flocks to $77.78 \%$ of the total, but in the paddy fields for only $4.5 \%$ and $13.58 \%$, in the mudflats for $10.4 \%$ and $8.64 \%$, respectively (Table 1). The distribution of families of cranes and groups of cranes also varied over the three wintering stages (Fig. 2). Group cranes in the early stage accounted for $60.95 \%$ and family cranes for $39.05 \%$. Both family and group cranes in the paddy fields accounted for the highest 


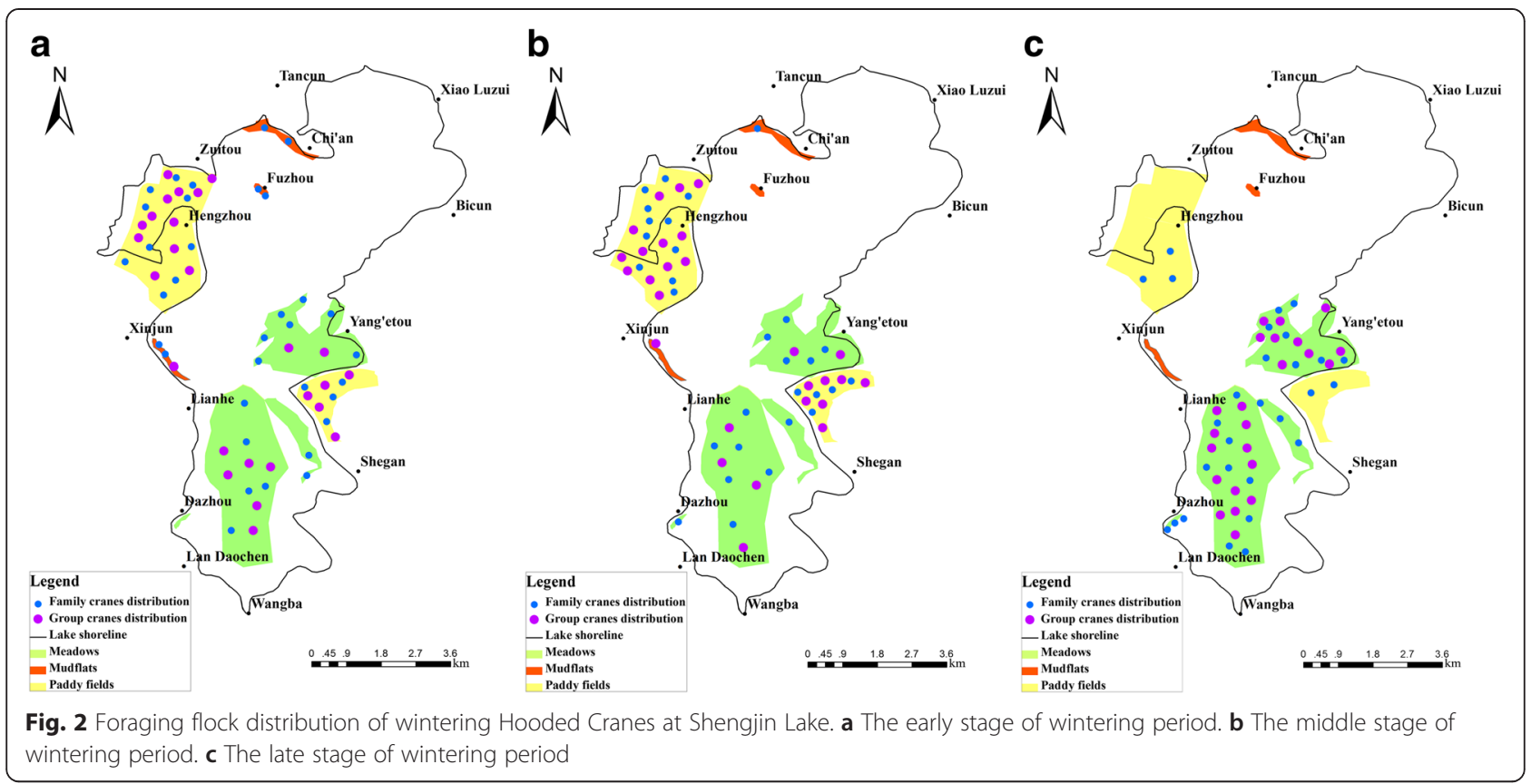

percentage, reaching $20.95 \%$ and $30.48 \%$ respectively (Fig. 2a). The percentage of group cranes increased to $78.89 \%$ in the middle stage while family cranes only accounted for $21.11 \%$. The paddy fields still had the highest percentages of the total number of family cranes, i.e., $12.22 \%$ and group cranes with $37.78 \%$ (Fig. 2b). The percentage of family cranes rose to $37.04 \%$ in the late winter period, while the group cranes accounted for $62.96 \%$. At this stage, meadows contained the largest number of both family and group cranes, $27.16 \%$ and $50.62 \%$, respectively (Fig. 2c).

\section{Spatial and temporal variations of foraging flocks}

There are significant differences in sizes of foraging flocks among the various habitats $\left(F_{2}, 273=5.797, p=\right.$ $0.003)$. The flocks in the paddy fields $(33.40 \pm 41.60, n=$
110) are markedly larger than those in the meadows (23.11 $\pm 30.43, n=112)$ and the mudflats $(15.41 \pm 16.54$, $n=54)$. There is no significant difference in the age composition of cranes between the three types of habitats $\left(F_{2,273}=0.836, p=0.434\right)$. As well, the size and the age composition of flocks did not change significantly with the change in the winter periods $(p>0.05)$.

During the wintering periods we investigated 90 flocks of family cranes and 186 flocks of group cranes. Although there were significant differences in flock sizes among foraging habitats $\left(F_{2,273}=5.797, p=0.003\right)$, the effect of foraging habitat on the flock of family cranes and group cranes varied as well. The size of the group cranes flock were significantly affected by habitat $\left(F_{2,183}=9.868\right.$, $p=0.000)$. The flocks of group cranes in the paddy fields $(50.286 \pm 43.97, n=76)$ were larger than those in the

Table 1 Composition and distribution of Hooded Cranes in three habitats

\begin{tabular}{|c|c|c|c|c|c|}
\hline \multirow[t]{2}{*}{ Period } & \multirow[t]{2}{*}{ Habitat } & \multirow{2}{*}{$\begin{array}{l}\text { Proportion of individual } \\
\text { cranes (\%) }\end{array}$} & \multicolumn{3}{|c|}{ Proportion of flocks (\%) } \\
\hline & & & Total & Family cranes & Group cranes \\
\hline \multirow[t]{3}{*}{ Early stage } & Paddy fields & 60.8 & 51.43 & 20.95 & 30.48 \\
\hline & Meadows & 28.8 & 27.62 & 10.48 & 17.14 \\
\hline & Mudflats & 10.4 & 20.98 & 7.62 & 13.33 \\
\hline \multirow[t]{3}{*}{ Middle stage } & Paddy fields & 70.8 & 50 & 12.22 & 37.78 \\
\hline & Meadows & 15 & 22.22 & 3.33 & 18.89 \\
\hline & Mudflats & 14.2 & 27.8 & 5.56 & 22.22 \\
\hline \multirow[t]{3}{*}{ Late stage } & Paddy fields & 4.5 & 13.58 & 7.41 & 6.17 \\
\hline & Meadows & 85.1 & 77.78 & 27.16 & 50.62 \\
\hline & Mudflats & 10.4 & 8.64 & 2.47 & 6.17 \\
\hline
\end{tabular}


meadows $(32.447 \pm 33.1, n=71)$ and those in the mudflats $(25.37 \pm 26.91, n=39)$. However, the flock size of family cranes did not appear to be significantly affected by habitat $\left(F_{2,87}=0.422, p=0.657\right)$.

The age composition of the flocks of family group cranes showed a considerable difference from that of the flock group cranes $\left(F_{1,274}=160.274, p=0.000\right)$. The age composition of family groups $(0.711 \pm 0.306, n=90)$ was larger than that of flock groups $(0.321 \pm 0.200, n=186)$, but there was no significant difference in the age composition of the over-wintering foraging flocks among the habitats $\left(F_{2,273}=0.836, p=0.434\right)$.

\section{Relationships between food abundance, disturbances and the pattern of foraging flocks}

Food abundance and disturbances in the three habitats showed significant differences $\left(F_{2,255}=179.11, p=0.00\right.$; $\left.F_{2,256}=144.49, p=0.00\right)$. Food abundance in the meadows $\left(96.37 \pm 57.88 \mathrm{~g} \cdot \mathrm{m}^{-2}, n=85\right)$ was notably higher than that in the paddy fields $\left(17.33 \pm 14.45 \mathrm{~g} \cdot \mathrm{m}^{-2}, n=91\right)$ and mudflats $\left(3.86 \pm 4.20 \mathrm{~g} \cdot \mathrm{m}^{-2}, n=82\right)$, while the intensity of disturbances in the paddy fields $(2.39 \pm 0.72, n=105)$ was higher than that in the meadows $(1.32 \pm 0.52, n=84)$ and mudflats $(0.89 \pm 0.51, n=69)$. Food abundance and disturbances in the meadows did not change significantly with the change in the wintering periods $\left(F_{2,82}=2.59, p=0.08\right.$; $\left.F_{2,81}=2.75, p=0.07\right)$. But these two conditions in the paddy fields changed significantly with the change of the wintering periods $\left(F_{2,88}=29.27, p=0.00 ; F_{2,103}=18.03\right.$, $p=0.00)$. A significant difference in food sources could be observed in the mudflats $\left(F_{2,79}=3.40, p=0.04\right)$, but not in disturbances $\left(F_{2,66}=2.60, p=0.08\right)$.

The results of the generalized linear model showed that food abundance and disturbances had different effects on the pattern of foraging flocks during the winter periods, while the effect of the size of the foraging flock was significant only at the middle stage. The age composition of flocks was markedly affected by food abundance during the early and late stages (Table 2). The effect of food abundance and disturbances over all stages was mainly embodied in the size of the flocks. The age composition of flocks was considerably effected by food abundance but not by disturbances (Table 2). Moreover, the combined action of food abundance and disturbances had a significant effect on the size of the foraging flock, but had no effect on the age composition of foraging flocks (Table 2).

\section{Discussion}

Temporal and spatial characteristics of foraging flocks

Birds flocking to forage is an adaptive strategy to guarantee survival and improve fitness (Beauchamp 2012). According to the optimal foraging theory, birds keep adjusting foraging strategies to fit the variation in food abundance and disturbances in different habitats (Brown and Kotler 2004; Macdonald et al. 2012). To obtain sufficient food and energy, the Hooded Crane selects flexible flock patterns and foraging distributions in order to adapt to changes in foraging habitats during the winter periods. Our research shows that the flock size of cranes showed clear changes in the three habitats, but changes in age composition were statistically not significant.

The Hooded Cranes arrive at their wintering grounds in succession after a long migration distances during the early stage. In order to avoid competition and to obtain food for a quick recovery, foraging flocks disperse and settle down in the various habitats. Paddy fields and meadows become major foraging habitats because the mudflats were less exposed (Zhao et al. 2013). Foraging flocks were found mainly in paddy fields, which may be explained by greater abundance of available food sources and the fact that rice

Table 2 The effect of food abundance and disturbances on the flock patterns of the Hooded Crane

\begin{tabular}{|c|c|c|c|c|c|}
\hline \multirow[t]{2}{*}{ Periods } & \multirow[t]{2}{*}{ Factors } & \multicolumn{2}{|c|}{ Flock size } & \multicolumn{2}{|c|}{ Age composition } \\
\hline & & $F$ & $p$ & $F$ & $p$ \\
\hline \multirow[t]{3}{*}{ Early stage } & food abundance & 0.394 & 0.999 & 9.284 & $0.000^{* * *}$ \\
\hline & disturbance & 0.076 & 0.999 & 0.929 & 0.498 \\
\hline & food abundance $\times$ disturbance & 0.103 & 0.902 & 4.984 & $0.013^{*}$ \\
\hline \multirow[t]{3}{*}{ Middle stage } & food abundance & 2.678 & $0.002^{* *}$ & 0.631 & 0.935 \\
\hline & disturbance & 4.502 & $0.006^{* *}$ & 1.135 & 0.360 \\
\hline & food abundance $\times$ disturbance & 2.824 & $0.027^{*}$ & 0.842 & 0.548 \\
\hline \multirow[t]{3}{*}{ Late stage } & food abundance & 0.207 & 1.000 & 1.62 & $0.041^{*}$ \\
\hline & disturbance & 0.126 & 0.996 & 1.747 & 0.120 \\
\hline & food abundance $\times$ disturbance & 0.109 & 0.990 & 1.41 & 0.237 \\
\hline \multirow[t]{3}{*}{ All stages } & food abundance & 33.512 & $0.000^{* * *}$ & 3.498 & $0.001^{* *}$ \\
\hline & disturbance & 3.944 & $0.000^{* * *}$ & 0.919 & 0.696 \\
\hline & food abundance $\times$ disturbance & 5.698 & $0.000^{* * *}$ & 0.574 & 0.980 \\
\hline
\end{tabular}

Samples: a) at all stages $n=341$; b) at the early stage $n=113$; c) at the middle stage $n=103$; d) at the late stage $n=125{ }^{*}=p<0.05 ;{ }^{* *}=p<0.01$; ${ }^{* * *}=p<0.001$ 
grains form a high-nutrition diet (Bishop and Li, 2002; Cai et al. 2014). But the intensity of disturbance was higher in the paddy fields. Both the number and the size of the foraging flocks were much larger than those in the meadows and mudflats. During the middle stage, food consumption by cranes increases when adverse weather conditions prevail (Yasué et al. 2003). Vegetation dormancy exacerbates the shortage of available food sources (Bishop and Li 2002). Still, the paddy fields remained the major foraging habitats. At this time, family flocks gradually assembled into the larger groups for cooperation in foraging (Zhou et al. 2010). The percentage of family groups decreased gradually and both the number and the size of flock groups rose markedly. Given the gradual reduction in food abundance on the paddy fields and the start of busy spring planting activities, paddy fields could no longer meet the food and safety demands of the foragers (Brown and Kotler 2004; Heithaus 2005; Santangeli and Dolman 2011). Therefore, the foraging flocks gradually concentrated on the meadows with less disturbance and richer food sources and managed to accumulate the energy necessary for returning to their breeding grounds.

\section{The effects of food abundance and disturbances on flock patterns}

Various studies have shown that food resources and disturbances are crucial factors that affect avian foraging flocks (Ma et al. 2003; Gyimesi et al. 2012; Baschuk et al. 2012) and our investigation supports this view. Variation in food abundance and disturbances in habitats had different effects on the foraging flocks of the Hooded Cranes during the winter periods, when flock sizes changed dramatically, similar to study research results about the foraging flocks of many other birds (Heithaus 2005; Severcan and Yamac 2011; Fuller et al. 2013). With abundant food and highly intensive disturbances, the flocks were concentrated and their size increased for cooperation in foraging. To avoid competition and maximize foraging benefits, flocks were dispersed and flock size would reduce with rich food and low disturbance.

Food abundance and disturbances in foraging habitats have slight effect on age composition, while the effect of food abundance was remarkable during the early and late stages. The age composition of cranes in flock groups was notably different from that of cranes in family flocks, which may be related to parental care and the characteristics of the habitat (Nystrand 2006; Avilés and Bednekoff 2007; $\mathrm{Xu}$ et al. 2013). Juveniles lack foraging experience and their foraging is inefficient (Avilés and Bednekoff 2007). They foraged with their parents. In order to guarantee their own survival and to take care of their offspring, the family group cranes prefer habitats with little disturbance and competition for resources (Alonso et al. 2004; Nystrand 2006).

\section{Conclusions}

Food abundance and disturbances in their foraging habitats affected the size and structure of foraging flocks of the Hooded Cranes during the winter periods. Changes in flock size were significant, given that the cranes responded to the degradation and loss of the wetland ecosystem. The size of flocks increased in the case of rich foods, despite disturbances in their foraging habitats, while the size of flocks was relatively reduced with the rich food and low disturbance. By trading off risks and costs, the cranes had flexible flock distributions and a variety of foraging habitats to maximize their benefits. The cranes continuously adjusted flock size to adapt to the changes in foraging habitats, of importance in improving their fitness.

\section{Competing interests}

The authors declare that they have no competing interests.

\section{Authors' contributions}

LY and LZ conceived and designed the experiments. LY performed the experiments and LY and LZ analyzed the data. LZ contributed the reagents/ materials/analysis tools. LY and LZ wrote the paper while LZ liaised with nature reserve authorities and obtained provincial guidance for field work. YW participated in the field work. All authors read and approved the final version of the manuscript.

\section{Acknowledgments}

The work was supported by the staff of the Shengjin Lake National Nature Reserve. We express appreciation to the National Natural Science Foundation of China (Grant no. 31172117, 31472020) and the Graduate Student Innovation Research Projects of Anhui University (YQH100270) for financial support. We thank Meng Zheng and Dr. Chunlin Li for their helpful comments and suggestions for this study.

\section{Author details}

${ }^{1}$ School of Resources and Environmental Engineering, Anhui University, Hefei 230601, China. ${ }^{2}$ Institute of Biodiversity and Wetland Ecology, Anhui University, Hefei 230601, China. ${ }^{3}$ Anhui Biodiversity Information Center, Hefei 230601, China. ${ }^{4}$ Shengjin Lake National Nature Reserve of Anhui Province, Dongzhi 247200, China.

Received: 2 March 2015 Accepted: 2 June 2015

Published online: 12 August 2015

\section{References}

Abramsky Z, Strauss E, Subach A, Kotler BP, Reichman A (1996) The effect of barn owls (Tyto alba) on the activity and microhabitat selection of Gerbillus allenbyi and G. pyramidum. Oecologia 105(3):313-319

Alonso JC, Bautista LM, Alonso JA (2004) Family-based territoriality vs flocking in wintering Common Cranes (Grus grus). J Avian Biol 35(5):434-444

Altmann J (1974) Observational study of behavior: sampling methods. Behaviour 49(3):227-267

Avilés JM (2003) Time budget and habitat use of the Common Crane wintering in Dehesas of southwestern Spain. Can J Zool 81(7):1233-1238

Avilés JM, Bednekoff PA (2007) How do vigilance and feeding by common cranes Grus grus depend on age, habitat, and flock size? Avian Biol 38(6):690-697

Azevedo CS, Ferraz JB, Tinoco HP, Young RJ, Rodrigues M (2010) Time-activity budget of greater rheas (Rhea americana, Aves) on a human-disturbed area: the role of habitat, time of the day, season and group size. Acta Ethol 13(2):109-117

Bahr DB, Bekoff M (1999) Predicting flock vigilance from simple passerine interactions: modelling with cellular automata. Anim Behav 58:831-839

Barta Z, Liker A, Mónus F (2004) The effects of predation risk on the use of social foraging tactics. Anim Behav 67:301-308

Barter M, Chen LW, Cao L, Lei G (2004) Waterbird Survey of the Middle and Lower Yangtze River Floodplain in Late January and Early February 2004. China Forestry Publishing House, Beijing 
Baschuk MS, Koper N, Wrubleski DA, Goldsborough G (2012) Effects of water depth, cover and food resources on habitat use of marsh birds and waterfowl in boreal wetlands of Manitoba, Canada. Waterbirds 35(1):44-55

Beauchamp G (2005) Does group foraging promote efficient exploitation of resources? Oikos 111(2):403-407

Beauchamp G (2009) How does food density influence vigilance in birds and mammals? Anim Behav 78:223-231

Beauchamp G (2012) Foraging speed in staging flocks of semipalmated sandpipers: evidence for scramble competition. Oecologia 169(4):975-980

Beauchamp G (2013) Social foragers adopt a riskier foraging mode in the centre of their groups. Biol Lett 9(6):1-3

Bekoff M (1995) Vigilance, flock size, and flock geometry: information gathering by western evening grosbeaks (Aves, Fringillidae). Ethology 13:150-161

BirdLife International (2014) Grus monacha. In: IUCN 2014. The IUCN Red List of Threatened Species. Version 2014.3., Http://www.iucnredlist.org

Bishop MA, Li FS (2002) Effects of farming practices in Tibet on wintering Black-necked Crane (Grus nigricollis) diet and food availability. Biodiv Sci 10(4):393-398

Brown JS, Kotler BP (2004) Hazardous duty pay and the foraging cost of predation. Ecol Lett 7(10):999-1014

Cai TL, Huettmann F, Guo YM (2014) Using stochastic gradient boosting to infer stopover habitat selection and distribution of Hooded Cranes Grus monacha during spring migration in Lindian, Northeast China. PLoS One 9(2):1-12

Chen JY, Zhou LZ (2011) Guild structure of wintering waterbird assemblages in shallow lakes along Yangtze River in Anhui Province, China. Acta Ecol Sin 31(18):5323-5331

Cong P, Rees EC, Sun MM, Mj Z, Cao L, Barter M (2011) A comparison of behaviour and habitat use by Bewick's Swans Cygnus columbianus bewickii at wintering sites in China and Europe: preliminary observations. Wildfowl 61:52-73

Conradt $L$ (1998) Measuring the degree of sexual segregation in group-living animals. J Anim Ecol 67:217-226

Czech HA, Parsons KC (2002) Agricultural wetlands and waterbirds: a review. Waterbirds 25:56-65

Elgar MA (1989) Predator vigilance and group size in mammals and birds: a critical review of the empirical evidence. Biol Rev 64:13-33

Fox AD, Cao L, Zhang Y, Barter M, Zhao MJ, Meng FJ, Wang SL (2011) Declines in the tuber-feeding waterbird guild at Shengjin Lake National Nature Reserve, China - a barometer of submerged macrophyte collapse. Aquat Conserve 21(1):82-91

Fuller RA, Bearhop S, Metcalfe NB, Piersma T (2013) The effect of group size on vigilance in Ruddy Turnstones Arenaria interpres varies with foraging habitat Ibis 155(2):246-257

Gyimesi A, Franken MS, Feige N, Nolet BA (2012) Human disturbance of Bewick's Swans is reflected in giving-up net energy intake rate, but not in giving-up food density. Ibis 154(4):781-790

Hansen BB, Aanes R, Herfindal I, Sæther BE, Henriksen S (2009) Winter habitat-space use in a large arctic herbivore facing contrasting forage abundance. Polar Biol 32(7):971-984

Heithaus MR (2005) Habitat use and group size of pied cormorants (Phalacrocorax varius) in a seagrass ecosystem: possible effects of food abundance and predation risk. Mar Biol 147(1):27-35

Heithaus MR, Dill LM (2002) Food availability and tiger shark predation risk affects bottlenose dolphin habitat use. Ecology 83:480-491

Jiang HX, Xu WB, Qian FW, Chu GZ (2007) Impact of habitat evolvement and human disturbance on wintering water birds in Shengjin Lake of Anhui Province, China. Chin J Appl Ecol 18(8):1832-1836

Jing K, Ma ZJ, Li B, Li JH, Chen JK (2007) Foraging strategies involved in habitat use of shorebirds at the intertidal area of Chongming Dongtan, China. Ecol Res 22(4):559-570

Kotler BP, Brown JS, Hasson O (1991) The specter of predation: factors affecting gerbil foraging behavior and rates of owl predation. Ecology 72(6):2249-2260

Kuwae T, Miyoshi E, Sassa S, Watabe Y (2010) Foraging mode shift in varying environmental conditions by dunlin Calidris alpina. Mar Ecol Prog Ser 406:281-289

Li CL, Zhou LZ, Li HK, Jiang ZG (2011) Effects of foraging mode and group pattern on vigilance behavior in water birds: a case study of mallard and black-winged stilt. Belg J Zool 141(2):45-54

Li HC, Ding TS, Tsai CF, Hsu FH (2012) Effects of habitat type and group size on foraging and vigilance behaviors of the Red Collared Dove Streptopelia tranquebarica. Taiwania 57(2):99-105
Lima SL (1998) Stress and decision making under the risk of predation: recent developments from behavioral, reproductive, and ecological perspectives. Adv Stud Behav 27:215-290

Lima SL, Dill LM (1990) Behavioral decision making under the risk of predation: a review and prospectus. Can J Zool 68(4):619-640

Liu ZY, Xu WB, Wang QS, Shi KC, Xu JS, Yu GQ (2001) Environmental carrying capacity for over-wintering Hooded Cranes in Shengjin Lake. Resour Environ Yangtze Basi 10(5):454-459

Liu Q, Yang XJ, Zhu JG, Zhao JL, Yu HZ (2008) Flock of black-necked crane wintering at Napahai nature reserve, China. Zool Res 29(5):553-560

Luo JM, Wang YJ, Yang F, Liu ZJ (2012) Effects of human disturbance on the Hooded Crane (Grus monacha) at stopover sites in northeastern China. Chinese Birds 3:206-216

Ma ZJ, Li B, Jing K, Zhao B, Tang SM, Chen JK (2003) Effects of tidewater on the feeding ecology of Hooded Crane (Grus monacha) and conservation of their wintering habitats at Chongming Dongtan, China. Ecol Res 18(3):321-329

Macdonald EC, Ginn MG, Hamilton DJ (2012) Variability in foraging behavior and implications for diet breadth among Semipalmated sandpipers staging in the upper bay of Fyndy. Condor 114(1):135-144

Masatomi H (2004) Individual (non-social) behavioral acts of Hooded Cranes (Grus monacha) wintering in Izumi, Japan. J Ethol 22:69-83

Michelena P, Deneubourg JL (2011) How group size affects vigilance dynamics and time allocation patterns: the key role of imitation and tempo. PLoS One 6(4):1-9

Nystrand M (2006) Influence of age, kinship, and large-scale habitat quality on local foraging choices of Siberian Jays. Behav Ecol 17:503-509

Santangeli A, Dolman PM (2011) Density and habitat preferences of male little bustard across contrasting agro-pastoral landscapes in Sardinia (Italy). Eur J Wildl Res 57(4):805-815

Severcan Ç, Yamac E (2011) The effects of flock size and human presence on vigilance and feeding behavior in the Eurasian Coot (Fulica atra) during breeding season. Acta Ethol 14(1):51-56

Sirot E, Maes P, Gélinaud G (2012) Movements and conflicts in a flock of foraging Black-Tailed Godwits (Limosa limosa): the influence of feeding rates on behavioural decisions. Ethology 118(2):127-134

Terence PB, Sandra MC, Robert GW (2004) Landsat TM inventory and assessment of waterbird habitat in the southern altiplano of South America. Wetland Ecol Manage 12:563-573

Wang QS (1988) The Hooded Cranes. Chin J zool 23(4):30-34

Wang K, Yang XJ, Zhao JL, Yu HZ, Min L (2009) Relations of daily activity patterns of age and flock of wintering Black-necked Crane (Grus nigricollis) at Napa Lake, Shangri-La in Yunnan. Zool Res 30:74-82

Wang Z, Li ZQ, Beauchamp G, Jiang ZG (2011) Flock size and human disturbance affect vigilance of endangered red-crowned cranes (Grus japonensis). Biolog Conserv 144(1):101-105

Wood C, Qiao Y, Li P, Ding P, Lu BZ, Xi YM (2010) Implications of rice agriculture for wild birds in China. Waterbirds 33(1):30-43

Xu LL, Xu WB, Sun QY, Zhou ZZ, Shen J, Zhao XX (2008) Flora and vegetation in Shengjin Lake. J Wuhan Bot Res 27(3):264-270

Xu F, Ma M, Yang WK, Blank D, Ding P, Zhang T (2013) Vigilance in Black -Necked Cranes: effects of predation vulnerability and flock size. Wilson J Ornithol 125(1):208-212

Yasué M (2005) The effects of human presence, flock size and prey density on shorebird foraging rates. J Ethol 23(2):199-204

Yasué M, Quinn JL, Cresswell W (2003) Multiple effects of weather on the starvation and predation risk tradeoff in choice of feeding location in redshanks. Funct Ecol 17:727-736

Zhao FT, Zhou LZ, Xu WB (2013) Habitat utilization and resource partitioning of wintering Hooded Cranes and three goose species at Shengjin Lake. Chinese Birds 4(4):281-290

Zhou B, Zhou LZ, Chen JY, Xu WB, Cheng YQ (2009) Assemblage dynamics and territorial behavior of Hooded Cranes wintering in Shengjin Lake. Chin Wildlife 30(3):133-136

Zhou B, Zhou LZ, Chen JY, Cheng YQ, Xu WB (2010) Diurnal time-activity budgets of wintering Hooded Cranes (Grus monacha) in Shengjin Lake, China. Waterbirds 33(1):110-115 